\title{
Interfascial Plane Blocks Reduce Postoperative Pain and Morphine Consumption in Thoracic Outlet Decompression
}

Citation for published version (APA):

Goeteyn, J., van den Broek, R., Bouwman, A., Pesser, N., van Nuenen, B., van Sambeek, M., Houterman, S., Teijink, J., \& Versyck, B. (2020). Interfascial Plane Blocks Reduce Postoperative Pain and Morphine Consumption in Thoracic Outlet Decompression. Annals of Vascular Surgery, 66, 301-308. https://doi.org/10.1016/j.avsg.2019.12.005

Document status and date:

Published: 01/07/2020

DOI:

10.1016/j.avsg.2019.12.005

Document Version:

Publisher's PDF, also known as Version of record

\section{Document license:}

Taverne

Please check the document version of this publication:

- A submitted manuscript is the version of the article upon submission and before peer-review. There can be important differences between the submitted version and the official published version of record.

People interested in the research are advised to contact the author for the final version of the publication, or visit the DOI to the publisher's website.

- The final author version and the galley proof are versions of the publication after peer review.

- The final published version features the final layout of the paper including the volume, issue and page numbers.

Link to publication

\footnotetext{
General rights rights.

- You may freely distribute the URL identifying the publication in the public portal. please follow below link for the End User Agreement:

www.umlib.nl/taverne-license

Take down policy

If you believe that this document breaches copyright please contact us at:

repository@maastrichtuniversity.nl

providing details and we will investigate your claim.
}

Copyright and moral rights for the publications made accessible in the public portal are retained by the authors and/or other copyright owners and it is a condition of accessing publications that users recognise and abide by the legal requirements associated with these

- Users may download and print one copy of any publication from the public portal for the purpose of private study or research.

- You may not further distribute the material or use it for any profit-making activity or commercial gain

If the publication is distributed under the terms of Article $25 \mathrm{fa}$ of the Dutch Copyright Act, indicated by the "Taverne" license above, 


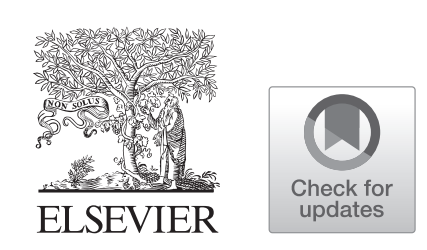

\title{
Interfascial Plane Blocks Reduce Postoperative Pain and Morphine Consumption in Thoracic Outlet Decompression
}

\author{
Jens Goeteyn, Renee van den Broek, ${ }^{2}$ Arthur Bouwman, ${ }^{2}$ Niels Pesser, ${ }^{1}$ Bart van Nuenen, ${ }^{3}$ \\ Marc van Sambeek, Saskia Houterman, ${ }^{1,4,3}$ Joep Teijink, ${ }^{1,5}$ and Barbara Versyck, ${ }^{2}$ \\ Eindhoven, the Netherlands
}

\begin{abstract}
Background: Postoperative analgesia in patients undergoing transaxillary thoracic outlet decompression (TATOD) is challenging because of the invasive surgery, the complex innervation of the axillary region, and the preoperative use of opioids by many patients. Commonly, postoperative pain is managed with additional opioids that introduce well-known sideeffects. To investigate the analgesic efficacy of 2 novel regional anesthesia techniques, we performed a retrospective study comparing the combined pectoral block type 1 and erector spinae block (PECS $1+$ ESB) and the pectoral block type 2 (PECS 2) and systemic intravenous opioids regimen (no block) in patients undergoing TATOD.

Materials and methods: We performed 10 PECS 1 + ESB and 10 PECS 2 blocks in patients undergoing TATOD. Twenty patients were randomly selected as controls. The primary endpoint was pain. Secondary endpoints were opioid use, nausea, and vomiting.

Results: Postoperative maximal numeric rating scale scores on recovery were significantly lower in patients receiving either a PECS $1+$ ESB or a PECS 2 block compared with controls without block (no block: median 6.00, interquartile range [IQR] 3.00; PECS 1 + ESB: median 4.50, IQR 4.00; PECS 2: median 4.00, IQR 5.00; $P=0.031$ ). Postoperative intravenous morphine consumption was $43 \%$ lower in the PECS $1+$ ESB group and $56 \%$ lower in the PECS 2 group compared with the group with no block (oral morphine equivalents; no block: mean $16.05 \pm$ SD $6.79 \mathrm{mg}$; PECS $1+$ ESB mean $9.05 \pm$ SD $6.24 \mathrm{mg}$; PECS 2: mean $7.00 \pm$ SD 6.16; $P=0.03$ and $P=0.003$, respectively). There was no statistical difference in both nausea and vomitus (no block $45 \%$ nausea and $30 \%$ vomitus, PECS $1+$ ESB $40 \%$ nausea and $20 \%$ vomitus, PECS $210 \%$ nausea and $0 \%$ vomitus, $P=0.17$ and $P=0.14$, respectively). Conclusions: There was a significant reduction in postoperative pain and opioid consumption for patients treated with either the PECS 1 + ESB block or PECS 2.
\end{abstract}

\footnotetext{
${ }^{1}$ Department of Vascular Surgery, Catharina Hospital, Eindhoven, the Netherlands.

${ }^{2}$ Department of Anaesthesiology, Catharina Hospital, Eindhoven, the Netherlands.

${ }^{3}$ Department of Neurology, Catharina Hospital, Eindhoven, the Netherlands.

${ }^{4}$ Department of Education and Research, Catharina Hospital, Eindhoven, the Netherlands.

${ }^{5}$ Faculty of Health, Medicine and Life Sciences, Department of Epidemiology, CAPHRI School for Public Health and Primary Care, Maastricht University, Maastricht, the Netherlands.
}

Correspondence to: Jens Goeteyn, Catharina Ziekenhuis Eindhoven, Michelangelolaan 2, 5623 EJ, Eindhoven, Netherland; E-mail: jens.goeteyn@catharinaziekenhuis.nl

Ann Vasc Surg 2020; 66: 301-308

https://doi.org/10.1016/j.avsg.2019.12.005

(C) 2019 Elsevier Inc. All rights reserved.

Manuscript received: October 6, 2019; manuscript accepted: December 1,

2019; published online: 16 December 2019 


\section{INTRODUCTION}

Thoracic outlet syndrome (TOS) is a group of potentially disabling conditions thought to be caused by the compression of neurovascular structures going to the upper extremity. ${ }^{1-4}$ Three distinct types of TOS exist: arterial, venous, and neurogenic TOS, by compression of the artery, vein, or plexus, respectively. ${ }^{1}$ In certain cases-when patients do not improve with physiotherapy-surgery can be performed to release the compressed neurovascular structures at the thoracic outlet. ${ }^{1,5,6}$ Several approaches (transaxillary, supraclavicular, infraclavicular, and transthoracic) are used for surgical decompression. ${ }^{7}$ In our center, we perform a transaxillary thoracic outlet decompression (TATOD) with resection of the first rib, partial scalenectomy, and lysis of either the plexus, vein, or artery. In every patient with pain over the pectoral minor insertion, a tenotomy of the most proximal 4$5 \mathrm{~cm}$ of the pectoral minor muscle is performed as well during the TATOD procedure.

Postoperative analgesia in TATOD is difficult because of the extensive nature of the surgery, the complex innervation of the thoracic wall and axillary region, and the limited possibilities of oral pain relief in patients already using oral pain relief on a daily base. ${ }^{8,9}$ Commonly, pain is managed with additional opioids, which introduces wellknown side effects like nausea, vomitus, constipation, drowsiness, and respiratory depression. This ultimately leads to worse patient experience and longer hospital stay. ${ }^{10-12}$

Regional anesthesia techniques are a good supplement to reduce postoperative pain and reduce the need for opioids. These techniques are part of a multimodal analgesia approach. ${ }^{13}$ Techniques such as thoracic paravertebral, thoracic epidural, and interscalene brachial plexus blocks are routinely used in thoracic and axillary surgery. ${ }^{8,12,14-18}$ However, these techniques are not easily performed and have their own complications. The thoracic interfascial plane blocks are easy alternatives to provide regional anesthesia with a very low risk of complications. ${ }^{9,19,20}$ The pectoral nerve blocks (PECS) type I and type II and the erector spinae block (ESB) are thoracic interfascial plane blocks providing analgesia of the thoracic wall and axillary region. ${ }^{8,12,14-18}$

We hypothesized that the combined pectoral block type 1 and erector spinae block (PECS $1+$ ESB) and PECS 2 might provide additional analgesia in patients undergoing TATOD, blocking intercostal nerves and sensory brachial plexus nerves. The motor branches of the brachial plexus compressed at the thoracic outlet are not blocked with these techniques. This is an advantage as these techniques do not interfere with motor function of the arm and thus, do not obscure early postoperative complications of the brachial plexus nerves after TATOD surgery.

After introduction of both the PECS $1+$ ESB and PECS 2 techniques in our clinical practice, we retrospectively evaluated pain and opioid consumption in patients diagnosed with TOS treated with TATOD. Our secondary outcome parameters were postoperative morphine consumption and postoperative nausea and vomitus (PONV).

\section{MATERIALS AND METHODS}

This retrospective case-control study was approved by the Medical Research Ethics Committees United (W18.227).

\section{Case and Control Selection}

In a 6-month period (May 2018-October 2018), we performed 20 thoracic wall blocks in patients undergoing TATOD: 10 patients with PECS $1+$ blocks combined with an ESB and 10 patients with a PECS 2 block. These blocks were part of clinical expertise and performed by the same anesthesiologist (B.V.). All patients undergoing TATOD were asked by this anesthesiologist if they would like a supplementary analgesia through a block. If a case was identified, a control patient treated with TATOD without the thoracic interfascial plane block in the same time period was included as a control. In total, 20 controls were selected. All patients were treated by the same surgeon, who agreed with the implementation of the blocks. All participating patients consented to the anonymous use of their data for study purposes. This question to consent is part of the routine preoperative anesthesia questionnaire, and patients are free to accept or not. There is ample time (>1 week) between the preoperative consultation and the date of surgery for patients to re-evaluate their consent.

\section{Analgesia Technique}

The axillary region is innervated by the thoracic spinal nerves and branches of the brachial plexus. The PECS 1 is an interfascial plane block in which local anesthetic is deposited between the pectoralis major and minor muscles, blocking the lateral and medial pectoral nerves, provided by the brachial plexus and the intercostobrachial nerve. $9,19,21,22$ This block provides pain relief in the area of the pectoral major muscle and is used in breast surgery, breast 
expander surgery, catheter surgery, and pacemaker insertion. $^{23}$

The PECS 2 is a modification of the PECS 1 where an additional deposit of local anesthetic is injected between the pectoralis minor and serratus anterior muscles. This blocks the lateral branches of at least the T2-T4 spinal nerves and the long thoracic nerve, as well as the intercostobrachial nerve and the lateral and medial pectoral nerves from the PECS 1 deposit. The PECS 2 block provides pain relief for the pectoral and axillary region and is suitable for more extensive surgery: mastectomy and axillary clearance. ${ }^{23-26}$

The ESB is administered beneath the erector spinae muscle group, blocking dorsal and ventral rami of the spinal nerves causing sensory blockade over the dorsolateral and anterolateral thorax, provided by the spinal nerves ${ }^{20,27-31}$

Erector Spinae Block. The patient is placed in a lateral decubitus with the side of interest upward. A curve array probe or a high-frequency linear probe, depending on BMI of the patient, is placed in a longitudinal position $2-3 \mathrm{~cm}$ lateral to the vertebral column. The erector spinae muscles are identified in relation to the ipsilateral fifth thoracic vertebra (T5) transverse process. A needle is inserted with an in-plane technique in a cephalad to caudal direction until bone contact with the top of the transverse process is reached. After slight retraction of the needle, $20 \mathrm{~mL}$ of $0.5 \%$ ropivacaine hydrochloride is injected.

Pectoral Nerves Block Type 1. The patient is in supine position. A high-frequency linear probe is placed horizontally at the level of the third rib and vertically below the lateral third of the clavicle. Then the probe is rotated $45^{\circ}$ counterclockwise. The corresponding ultrasound image shows the pectoralis major and minor muscles and the pectoral branch of the thoraco-acromial artery in the interfascial plane between both muscles. The needle is introduced in plane from medial to lateral and 20 cc of $0.5 \%$ ropivacaine is injected in this interfascial plane. In addition to a PECS 1 block, in a PECS 2 block, an instillation of $20 \mathrm{~mL}$ of $0.5 \%$ ropivacaine hydrochloride is injected underneath the pectoralis minor muscle. If necessary, the local anesthetic is diluted with saline to achieve the right amount of volume without exceeding the maximal dose of $3 \mathrm{mg} / \mathrm{kg}$ ropivacaine.

\section{Preoperative Management}

As part of the standard protocol, all patients were given an intravenous (IV) access and receive acetaminophen as part of the preoperative management.

\section{Intraoperative Management}

On arrival in the OR, standard American Society of Anesthesiologists (ASA) monitoring was applied, and IV access was obtained. After completion of the sign-in procedure, general anesthesia (GA) was induced. After induction of GA, the PECS $1+$ ESB or the PECS 2 block was performed as described. Surgery was commenced 10 min after finalizing the block.

\section{Postoperative Management}

At the postanesthesia care unit (PACU) and ward, postsurgical pain management was performed as per the hospital's postoperative pain protocol. Patients are clinically assessed in a routine fashion for postoperative complications. Nausea, vomiting, and numeric rating scale (NRS) scores are documented by the PACU nurses. If a patient has an NRS score more than 3, IV boluses of morphine ( $1 \mathrm{mg} / \mathrm{mL}$ ) are titrated until pain relief with NRS $<4$ was achieved. The maximum amount of morphine is decided by the attending anesthesiologist and does not exceed $20 \mathrm{mg}$. Ketamine is given to reduce postoperative pain, if morphine alone is inadequate (NRS $>3$, after morphine titration). All patients received standard PONV prophylaxis consisting of granisetron $1 \mathrm{mg}$ and dexamethasone $4 \mathrm{mg}$ during surgery. Patients were discharged from the PACU if Aldrete's scores $\geq 8$, NRS scores $<3$, and PONV was absent or treated. At the surgical ward, a medical assessment is documented routinely at 4 different time intervals. All medication administration is documented in the patient's clinical file. Postoperative pain at the surgical ward is managed with paracetamol, nonsteroid anti-inflammatory agents, and oral opioids.

\section{Data Collection}

All data were collected from the electronic patients file. The attending anesthesiologist collected data with regard to the anesthesia and surgical procedure. This was performed to evaluate the results of these blocks, based on clinical expertise. Nurses and surgical residents documented the patient's status on the PACU and the surgical ward as part of standard practice. Morphine and sufentanil dosages were converted to morphine equivalent dose (MED). Oral opioids, only administered at the surgical ward, are not included in the calculation of the MED. We collected data on 4 different time points: preoperative, at the PACU, during the evening round at the ward, and the following morning. Because a local block only acts for a short period of 
Table I. Demographic data for patients without thoracic wall block, a PECS $1+$ ESB block and a PECS 2 block

\begin{tabular}{|c|c|c|c|c|c|c|c|}
\hline \multirow{2}{*}{ Variable } & \multirow{2}{*}{\multicolumn{2}{|c|}{$\frac{\text { No block }}{(n=20)}$}} & \multirow{2}{*}{\multicolumn{2}{|c|}{$\frac{\operatorname{PECS} 1+\mathrm{ESB}}{(n=10)}$}} & \multirow{2}{*}{\multicolumn{2}{|c|}{$\frac{\operatorname{PECS} 2}{(n=10)}$}} & \multirow{2}{*}{$P$-value } \\
\hline & & & & & & & \\
\hline Age, (y) & 38.00 & 17.00 & 40.50 & 30.00 & 45.00 & 27.00 & 0.41 \\
\hline $\operatorname{Sex}(M / F)$ & $3 / 17$ & & $3 / 7$ & & $2 / 8$ & & 0.63 \\
\hline BMI $\left(\mathrm{kg} / \mathrm{m}^{2}\right)$ & 23.35 & 7.28 & 24.60 & 5.43 & 24.70 & 7.97 & 0.54 \\
\hline Length of surgery, (h) & $1: 12$ & $0: 15$ & $1: 10$ & $0: 26$ & $1: 09$ & $0: 10$ & 0.54 \\
\hline NTOS/VTOS/ATOS & $17 / 3 / 0$ & & $9 / 1 / 0$ & & $10 / 0 / 0$ & & \\
\hline
\end{tabular}

time (+- 4 hr), the data at admission and during morning rounds postoperatively will serve as baseline data.

\section{Statistical Analysis}

The primary endpoint was the NRS score. Secondary endpoints were opioid use, nausea, and vomitus. Continuous variables were presented as mean and standard deviation (SD) or median and interquartile range (IQR), depending on normality. Categorical demographic variables were reported as number. Percentages were used to report on PONV. Differences in normal distributed continuous variables across the 3 groups were tested using a one-way analysis of variance. Differences between groups were estimated using the Bonferroni correction. Differences in not-normal distributed continuous variables were compared with a Kruskal-Wallis test across the 3 groups and with the Mann-Whitney $U$-test comparing 2 groups. The Bonferroni correction was used $(P$-value $<0.016)$ to correct for multiple comparison. Differences in categorical variables between the 3 groups were tested using the Fisher's exact test. A $P$ value $<0.05$ was considered statistically significant when comparing 3 groups. Statistical analyses were performed using SPSS, version 25 (SPSS Inc, Chicago IL).

\section{RESULTS}

Patient demographics, ASA classification, type of TOS, and duration of surgery were comparable in all groups (Table I). The length of stay was comparable between all groups. In total, 3 VTOS patients and 17 NTOS patients were treated in the 'no block' group, 1 VTOS patient and 9 NTOS patients were treated in the PECS $1+$ ESB group, and 10 NTOS patients were treated in the PECS 2 group. There were no patients with ATOS. The NRS scores on admission of the patient were similar in all groups (no block: median 1.50, IQR 4.00; PECS $1+$ ESB: median 3.50, IQR 4.00; PECS 2: median 3.00, IQR 4.00; $P=0.40$ ) (Table II and Fig. 1). Comparing the 3 groups, postoperative maximal NRS scores on the recovery were significantly lower in patients with no block (no block: median 6.00, IQR 3.00; PECS 1 + ESB: median 4.50, IQR 4.00; PECS 2: median 4.00, IQR 5.00; $P=0.031$ ). There was no statistical difference between NRS scores at the evening $(P=0.060)$ and the next morning $(P=0.13)$.

When comparing groups, a trend for lower pain scores was seen on the recovery in patients receiving a thoracic wall block than in no block patients, however statistically nonsignificant $(P=0.019$ for PECS $1+$ ESB versus no block and $P=0.069$ for PECS 2 versus no block). If we compare the pain scores of PECS $1+$ ESB to the PECS 2 group, no statistical differences were found (Table II).

Postoperative IV morphine consumption was lowered by $43 \%$ in the PECS $1+$ ESB and by $56 \%$ in the PECS 2 compared with no block (oral morphine equivalents: no block: mean $16.05 \pm \mathrm{SD}$ 6.79 mg; PECS $1+$ ESB mean $9.05 \pm$ SD $6.24 \mathrm{mg}$; PECS 2: mean: PECS $27.00 \pm$ SD 6.16; $P=0.029$ and $P=0.003$, respectively). Intraoperative pain relief with sufentanil was comparable in all groups (no block: mean 68.40 MED \pm SD 23.06; PECS $1+$ ESB mean 57.60 MED \pm SD 20.23; PECS 2: mean $56.40 \pm$ SD 20.45, $P=0.27$ ) (Table III).

In the PECS $1+$ ESB group, 4 patients $(40 \%)$ experienced nausea and 2 patients $(20 \%)$ vomited. In the PECS 2 group, 1 patient (10\%) experienced nausea and no patients ( $0 \%$ ) suffered from vomiting (Table IV). The no-block group had 9 patients with nausea $(45 \%)$ and 6 patients $(30 \%)$ who vomited after surgery. For both nausea $(P=0.17)$ and vomiting $(P=0.14)$, no statistically significant difference was found. No patients were treated with IV morphine in the ward. 
Table II. Postoperative pain scales and pain relief for patients without thoracic wall block, a PECS 1 + ESB block and a PECS 2 block

\begin{tabular}{|c|c|c|c|c|c|c|c|c|c|c|}
\hline \multirow[b]{3}{*}{ Variable } & \multirow{2}{*}{\multicolumn{2}{|c|}{$\begin{array}{l}\text { No block } \\
(n=20)\end{array}$}} & \multicolumn{2}{|c|}{ PECS $1+$ ESB } & \multicolumn{2}{|l|}{ PECS 2} & \multirow{3}{*}{$\begin{array}{l}\text { Comparing } \\
\text { between } \\
\text { all groups }{ }^{\mathrm{a}}\end{array}$} & \multicolumn{3}{|l|}{ Significance } \\
\hline & & & $(n=10)$ & & $(n=10)$ & & & \multirow{2}{*}{$\begin{array}{l}\text { PECS } 1+\text { ESB } \\
\text { versus } \\
\text { No block }{ }^{\mathrm{b}} \\
P \text {-value }\end{array}$} & \multirow{2}{*}{$\begin{array}{l}\text { PECS } 2 \\
\text { versus } \\
\text { no block } \\
P \text {-value }\end{array}$} & \multirow{2}{*}{$\begin{array}{l}\text { PECS } 1+ \\
\text { ESB versus } \\
\text { PECS2 } \\
P \text {-value }\end{array}$} \\
\hline & Median & IQR & Median & IQR & Median & IQR & & & & \\
\hline NRS preoperative & 1.50 & 4.00 & 3.50 & 4.00 & 3.00 & 4.00 & 0.40 & 0.71 & 0.14 & 0.68 \\
\hline NRS maximal recovery & 6.00 & 3.00 & 4.50 & 4.00 & 4.00 & 5.00 & 0.031 & 0.019 & 0.067 & 0.68 \\
\hline NRS maximal ward & 3.00 & 3.00 & 1.50 & 2.00 & 2.00 & 2.00 & 0.060 & 0.039 & 0.11 & 0.53 \\
\hline NRS after $24 \mathrm{hr}$ & 4.00 & 3.00 & 2.00 & 3.00 & 2.50 & 3.00 & 0.13 & 0.050 & 0.59 & 0.25 \\
\hline
\end{tabular}

${ }^{\mathrm{a} C}$ Comparing between 3 groups using the Kruskal-Wallis test. Significance level: $P<0.05$.

${ }^{\mathrm{b}}$ Comparing between 2 groups using the Mann-Whitney $U$-test. Significance level: $P<0.016$ (adjusting for multiple testing).

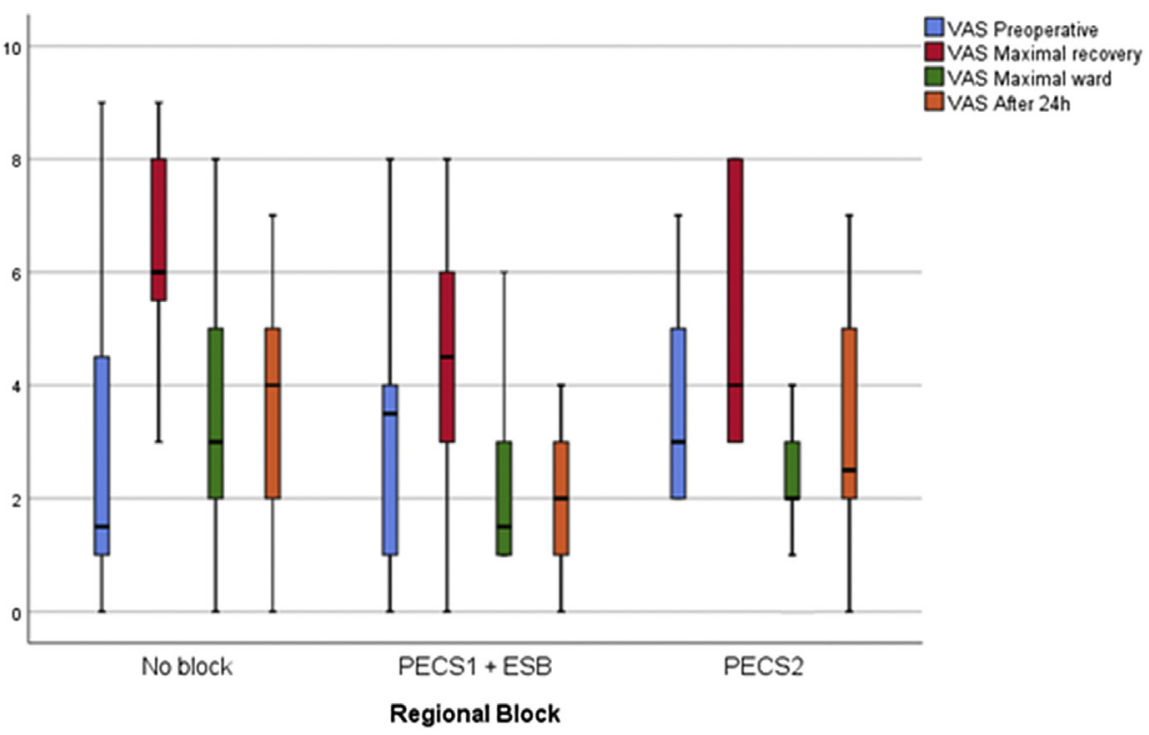

Fig. 1. Postoperative pain scores: NRS for patients without thoracic wall block, a PECS $1+$ ESB block and a PECS 2 block.

\section{DISCUSSION}

This case-control study compared the PECS $1+$ ESB block and PECS 2 block with the standard of care and demonstrated less postoperative pain on the recovery with a reduced need for morphine administration. Morphine consumption is associated with well-documented side effects such as PONV, drowsiness, constipation, ileus, respiratory depression, and urinary retention. In this study, we only assessed nausea and vomiting as a side effect of morphine. As baseline demographic and preoperative NRS scales are similar in all groups, we belief we managed to sample representative groups of patients.

To our knowledge, this is the first report of the use of thoracic interfascial plane blocks in TOD surgery. If we compare our results with the use of thoracic interfascial plane blocks used in breast, axillary, or thoracic surgery, our findings are consistent. A recent meta-analysis about PECS blocks in breast and axillary surgery shows a decreased use of morphine within the first $24 \mathrm{hr}$ after surgery. ${ }^{26}$ The use of this plane block has also been described in thoracic surgery, cardiac surgery, and chronic thoracic pain cases. ${ }^{11,16,20,21,32,33}$ PECS blocks are easily performed and are able to relieve postoperative pain more effectively than traditional analgesics with a reduced need for opioids. ${ }^{20}$ There are only limited data comparing ESB with other techniques, as this technique was only conceived in 2016. A review of 242 cases reports a reduction in postoperative pain and opioid use in breast, thoracic, and 
Table III. Postoperative pain relief for patients without thoracic wall block, a PECS $1+$ ESB block and a PECS 2 block

\begin{tabular}{|c|c|c|c|c|c|c|c|c|c|}
\hline \multirow[b]{3}{*}{ Variable } & \multirow{2}{*}{\multicolumn{2}{|c|}{$\begin{array}{l}\text { No block } \\
(n=20)\end{array}$}} & \multicolumn{2}{|c|}{ PECS $1+$ ESB } & \multicolumn{2}{|l|}{ PECS 2} & \multicolumn{3}{|l|}{ Significance } \\
\hline & & & \multicolumn{2}{|c|}{$(n=10)$} & \multicolumn{2}{|c|}{$(n=10)$} & \multirow{2}{*}{$\begin{array}{l}\text { PECS 1 + ESB } \\
\text { versus } \\
\text { No block } \\
P \text {-value }\end{array}$} & \multirow{2}{*}{$\begin{array}{l}\text { PECS } 2 \\
\text { versus } \\
\text { no block } \\
P \text {-value }\end{array}$} & \multirow{2}{*}{$\begin{array}{l}\text { PECS } 1+\text { ESB } \\
\text { versus } \\
\text { PECS } 2 \\
P \text {-value }\end{array}$} \\
\hline & Mean & SD & Mean & SD & Mean & SD & & & \\
\hline $\begin{array}{l}\text { Sufentanil } \\
\quad \text { intraoperative (MED) }\end{array}$ & 68.40 & 23.06 & 57.60 & 20.23 & 56.40 & 20.45 & 0.63 & 0.49 & 1.000 \\
\hline $\begin{array}{l}\text { Morphine recovery } \\
\quad(\text { MED) }\end{array}$ & 16.05 & 6.79 & 9.05 & 6.24 & 7.00 & 6.16 & 0.029 & 0.003 & 1.000 \\
\hline
\end{tabular}

Table IV. PONV for patients without thoracic wall block, a PECS 1 + ESB block and a PECS 2 block

\begin{tabular}{|c|c|c|c|c|}
\hline & No block & PECS $1+$ ESB & PECS 2 & \\
\hline Variable & $(n=20)$ & $(n=10)$ & $(n=10)$ & $P$-value \\
\hline Nausea, \% & $45 \%$ & $40 \%$ & $10 \%$ & 0.17 \\
\hline Vomitus, \% & $30 \%$ & $20 \%$ & $0 \%$ & 0.14 \\
\hline
\end{tabular}

cardiac surgery cases. ${ }^{27,32,34}$ ESB was less effective in breast surgery than PECS blocks. ${ }^{27}$

In most (invasive) thoracic surgery, the paravertebral block (PVB) has taken over the place of the thoracic epidural analgesia (TEA) as the gold standard. ${ }^{8,18}$ However, the PVB is a complex technique with potentially serious side effects and requires a substantial amount of operating time to perform. This may explain why many anesthesiologists are not fond of using the PVB in daily routine. ${ }^{33}$

In our center, we first decided to perform a PECS 2 block for TATOD. Initial cases were promising; however, posterior thorax pain at the level of the scapula was still present. Therefore, we decided to perform a combination of the PECS 1 and ESB blocks to target the ventral and the lateralposterior side of the thorax, respectively. Nonetheless, patients reported similar pain complaints. Most likely, this pain at the scapula is due to the positioning and the traction onto the nerves during surgery (patients are placed onto their sides with the arm in anteversion and abducted up to $120^{\circ}$ ). As both blocks gave similar promising results, except for the shoulder pain, we decided to implement the PECS 2 block. As the block is performed after induction and the patient can stay supine to perform a PECS 2 block, it is easiest to implement in daily practice.

There is a significant decrease in NRS scores at the recovery comparing between the fascial plane block groups and the control group. There were no statistical differences comparing between both fascial plane groups. This is probably caused by the small numbers in the groups. Furthermore, we see a trend for lower NRS scores at the recovery and at the ward for both fascial plane blocks compared to the control group. Also, the PECS $1+$ ESB block shows a trend to last longer (as NRS scales in the evening are lower) and the PECS 2 block shows a trend to lower PONV levels. Both blocks show a decrease in morphine used postoperatively.

Our results show that the effect of a block is biggest at the PACU/recovery. The NRS scores $24 \mathrm{hr}$ after surgery are similar in all groups. This is consistent with the fact that the effect of ropivacaine hydrochloride lasts for 2-8 hr. Because there was no morphine administration at the surgical ward, there is no need to extend the effect of the locoregional blocks (through an indwelling catheter or adding steroids to the injectate). There was no difference in the length of stay. All patients were able to leave the hospital 1 day after surgery. If we compare with other centers, this is quite exceptional: the mean length of stay varies from 2 to 5 days. ${ }^{35-37}$ This is most likely explained by the efforts of the anesthesiology team to offer patients multimodal analgesia- of which local blocks are a part of. There are multiple publications that connect high levels of opioid prescription to a longer length of stay because of opioid-induced side effects. ${ }^{10,35,36}$ In a publication by the group of Karl Illig, they were able to reduce the length of stay after TATOD from 4 to 2.6 days by introducing multimodal analgesia (with nonsteroid anti-inflammatory agents and benzodiazepines mixed with lower dosage of opioids). ${ }^{36}$

The decision not to block the nerves of the brachial plexus itself can be discussed. Although 
the transaxillary approach for thoracic outlet decompression is still open surgery, the size of the incision and extent of surgical dissection is quite minimal. Blocking the nerves that are freed from the overlying tissue (although not blocking the rami of the thoracic spinal nerves) might provide patients with excellent pain relief. However, we are weary to block the motor nerves in the brachial plexus, leaving the patient with 'a dead arm' for up to $24 \mathrm{hr}$, obscuring possible complications and possibly increasing the length of stay. Therefore, it was a conscious decision of the anesthesiologist not to block any motor nerves of the brachial plexus.

There are several limitations to our study. This is a retrospective evaluation of a clinical implementation and therefore lacks all prospective, randomized, or placebo-controlled elements. Data collection was complete but was limited to the data that are routinely assessed at the PACU and ward. Therefore, only pain scores, opioid consumption, and the presence of nausea and vomiting were assessed in this research. Other side effects of morphine (drowsiness, urinary retention, constipation, and respiratory depression) are not routinely documented and could therefore not been included. We did not include oral opioid therapy in the calculation of total morphine consumption (MED). This might have affected outcomes. The number of patients in this study was small.

In this retrospective case-control study, we found a significant reduction in postoperative pain and opioid consumption for patients treated with either the PECS 1 + ESB block or PECS 2 block compared with no block in patients undergoing thoracic outlet decompression for TOS. There was a trend for less nausea and vomiting.

$J G$ : collecting data, statistical analyses, writing of article. $R v d B, A B, N P, J T, M v S$ : proofreading.

SH: statistical analyses and proofreading.

$B V$ : administering of interfascial plane blocks, collecting data, proofreading and writing of article.

There was no financial support for this study.

\section{REFERENCES}

1. Illig KA, Donahue D, Duncan A, et al. Reporting standards of the Society for Vascular Surgery for thoracic outlet syndrome: executive summary. J Vasc Surg 2016;64:797-802.

2. Kuwayama DP, Lund JR, Brantigan CO, et al. Choosing surgery for neurogenic TOS: the roles of physical exam, physical therapy, and imaging. Diagnostics (Basel) 2017;7:7-37.

3. Povlsen B, Hansson T, Povlsen SD. Treatment for thoracic outlet syndrome. Cochrane Database Syst Rev 2014;CD 007218.
4. Illig K. Thoracic Outlet Syndrome. New York: Springer, 2013. pages $\mathrm{cm} \mathrm{p}$.

5. Hosseinian MA, Loron AG, Soleimanifard Y. Evaluation of complications after surgical treatment of thoracic outlet syndrome. Korean J Thorac Cardiovasc Surg 2017;50:36-40.

6. Klaassen Z, Sorenson E, Tubbs RS, et al. Thoracic outlet syndrome: a neurological and vascular disorder. Clin Anat 2014;27:724-32.

7. Peek J, Vos CG, Ünlü Ç, et al. Outcome of surgical treatment for thoracic outlet syndrome: systematic review and metaanalysis. Ann Vasc Surg 2017;40:303-26.

8. Baidya DK, Khanna P, Maitra S. Analgesic efficacy and safety of thoracic paravertebral and epidural analgesia for thoracic surgery: a systematic review and meta-analysis. Interact Cardiovasc Thorac Surg 2014;18:626-35.

9. Blanco R. The 'pecs block': a novel technique for providing analgesia after breast surgery. Anaesthesia 2011;66:847-8.

10. Cozowicz C, Olson A, Poeran J, et al. Opioid prescription levels and postoperative outcomes in orthopedic surgery. Pain 2017;158:2422-30.

11. Soliman IE, Apuya JS, Fertal KM, et al. Intravenous versus epidural analgesia after surgical repair of pectus excavatum. Am J Ther 2009; 16:398-403.

12. Kulhari S, Bharti N, Bala I, et al. Efficacy of pectoral nerve block versus thoracic paravertebral block for postoperative analgesia after radical mastectomy: a randomized controlled trial. Br J Anaesth 2016;117:382-6.

13. Kehlet H, Dahl JB. The value of "multimodal" or "balanced analgesia" in postoperative pain treatment. Anesth Analg 1993;77:1048-56.

14. Fortier S, Hanna HA, Bernard A, et al. Comparison between systemic analgesia, continuous wound catheter analgesia and continuous thoracic paravertebral block: a randomised, controlled trial of postthoracotomy pain management. Eur J Anaesthesiol 2012;29:524-30.

15. George RS, Milton R, Chaudhuri N, et al. Totally endoscopic (VATS) first rib resection for thoracic outlet syndrome. Ann Thorac Surg 2017;103:241-5.

16. Cheng GS, Ilfeld BM. An evidence-based review of the efficacy of perioperative analgesic techniques for breast cancerrelated surgery. Pain Med 2017;18:1344-65.

17. Li NL, Yu BL, Hung CF. Paravertebral block plus thoracic wall block versus paravertebral block Alone for analgesia of modified radical mastectomy: a retrospective cohort study. PLoS One 2016;11:e0166227.

18. Yeung JH, Gates S, Naidu BV, et al. Paravertebral block versus thoracic epidural for patients undergoing thoracotomy. Cochrane Database Syst Rev 2016;2:CD009121.

19. Blanco R, Fajardo M, Parras Maldonado T. Ultrasound description of Pecs II (modified Pecs I): a novel approach to breast surgery. Rev Esp Anestesiol Reanim 2012;59:470-5.

20. Forero M, Adhikary SD, Lopez H, et al. The erector spinae plane block: a novel analgesic technique in thoracic neuropathic pain. Reg Anesth Pain Med 2016;41:621-7.

21. Versyck B, van Geffen GJ, Van Houwe P. Prospective double blind randomized placebo-controlled clinical trial of the pectoral nerves (Pecs) block type II. J Clin Anesth 2017;40:46-50.

22. Versyck B, Groen G, van Geffen GJ, et al. The pecs anesthetic blockade: a correlation between magnetic resonance imaging, ultrasound imaging, reconstructed cross-sectional anatomy and cross-sectional histology. Clin Anat 2019;32: $421-9$.

23. Versyck B, Van Houwe P, van Geffen GJ, et al. A qualitative systematic review of the pectoral nerves block type I and II. Acta Anaesthesiol Belg 2017;68:49-62. 
24. O'Scanaill P, Keane S, Wall V, et al. Single-shot pectoral plane (PECs I and PECs II) blocks versus continuous local anaesthetic infusion analgesia or both after nonambulatory breast-cancer surgery: a prospective, randomised, double-blind trial. Br J Anaesth 2018;120:846-53.

25. Othman AH, El-Rahman AM, El Sherif F. Efficacy and safety of ketamine added to local anesthetic in modified pectoral block for management of postoperative pain in patients undergoing modified radical mastectomy. Pain Physician 2016;19:485-94.

26. Singh PM, Borle A, Kaur M, et al. Opioid-sparing effects of the thoracic interfascial plane blocks: a meta-analysis of randomized controlled trials. Saudi J Anaesth 2018;12:103-11.

27. Gurkan Y, Aksu C, Kus A, et al. Ultrasound guided erector spinae plane block reduces postoperative opioid consumption following breast surgery: a randomized controlled study. J Clin Anesth 2018;50:65-8.

28. Adhikary SD, Pruett A, Forero M, et al. Erector spinae plane block as an alternative to epidural analgesia for postoperative analgesia following video-assisted thoracoscopic surgery: a case study and a literature review on the spread of local anaesthetic in the erector spinae plane. Indian J Anaesth 2018;62:75-8.

29. Chin KJ, Malhas L, Perlas A. The erector spinae plane block provides visceral abdominal analgesia in bariatric surgery: a report of 3 cases. Reg Anesth Pain Med 2017;42:372-6.
30. Forero M, Rajarathinam M, Adhikary S, et al. Continuous erector spinae plane block for rescue analgesia in thoracotomy after epidural failure: a case report. A A Case Rep 2017;8: 254-6.

31. Hamilton DL, Manickam B. Erector spinae plane block for pain relief in rib fractures. Br J Anaesth 2017;1 18:474-5.

32. Tsui BCH, Fonseca A, Munshey F, et al. The erector spinae plane (ESP) block: a pooled review of 242 cases. J Clin Anesth 2018;53:29-34.

33. Duale C, Gayraud G, Taheri H, et al. A French nationwide survey on anesthesiologist-perceived barriers to the use of epidural and paravertebral block in thoracic surgery. J Cardiothorac Vasc Anesth 2015;29:942-9.

34. Krishna SN, Chauhan S, Bhoi D, et al. Bilateral erector spinae plane block for acute post-surgical pain in adult cardiac surgical patients: a randomized controlled trial. J Cardiothorac Vasc Anesth 2019;33:368-75.

35. Caputo FJ, Wittenberg AM, Vemuri C, et al. Supraclavicular decompression for neurogenic thoracic outlet syndrome in adolescent and adult populations. J Vasc Surg 2013;57:149-57.

36. Wooster M, Reed D, Tanious A, et al. Postoperative pain management following thoracic outlet decompression. Ann Vasc Surg 2017;44:241-4.

37. Ann Freischlag J. A decade of excellent outcomes after surgical intervention: 538 patients with thoracic outlet syndrome. Trans Am Clin Climatol Assoc 2018;129:88-94. 